Nevșehir Bilim ve Teknoloji Dergisi TARGíd Özel Sayı 169-178 2016

DOI: 10.17100/nevbiltek.210983

URL: http://dx.doi.org/10.17100/nevbiltek.210983

\title{
Meyve Bahçelerinin Sulanmasında Güneş Enerjisinden Yararlanma Olanakları
}

\author{
Şaban Yılmaz ${ }^{1}$, Kenan Uçan ${ }^{2 *}$, Mualla Keten ${ }^{2}$, Nazime Narin ${ }^{2}$ \\ ${ }^{1}$ Kahramanmaraş Sütçü Imam Üniversitesi, Kahramanmaraş Meslek Yüksekokulu, Kahramanmaraş \\ ${ }^{2}$ Kahramanmaraş Sütçü Imam Üniversitesi, Ziraat Fakültesi, Biyosistem Mühendisliği Bölümü,,
}

Kahramanmaraş

Öz

Bu çalışma Kahramanmaraş Sütçü İmam Üniversitesi Ziraat Fakültesi Meyve Bahçesinin sulanmasında derin kuyudan elde edilen sulama suyunda kullanılan elektrik enerjisi yerine fotovoltaik enerjiden faydalanılması amaçlanmıştır. Bu kapsamda bölgenin iklim şartları dikkate alınarak bitkilerin sulama suyu ihtiyaçları, sulama aralığı ve uygulanması gereken sulama suyu miktarlarına bağlı olarak gerekli olan fotovoltaik (PV) sistem tasarlanarak maliyet analizi yapılmıştır. Maliyet analizinde 30 yıllık süre için sulama suyunun maliyeti $0.06 \mathrm{TLm}^{-3}$ olarak hesaplanmıştır. Yatırım maliyeti $9029 \mathrm{TL}$ olan sistem, sulama dışında yıllık $2071.8 \mathrm{kWh}$ elektrik enerji fazladan üretecektir. Üretilen enerji farklı amaçlar için kullanılabilir veya şebekeye verilerek 2014 fiyatlarıyla yaklaşık 621 TL ek gelir elde edilebilir. Alanın yıllık toplam sulama suyu ihtiyacı 5856.4 mm'dir. Sulama suyu miktarının en fazla olduğu Temmuz ve Ağustos aylarında güneşlenme süresine göre ihtiyaç duyulan sulama suyu miktarı $2 \mathrm{ls}^{-1}$ 'dir.

Anahtar Kelimeler: Güneş enerjisi, Tarımsal sulama, Fotovoltaik, Kahramanmaraş

\section{Possibilities of Solar Energy of Irrigation in Orchards}

\begin{abstract}
In this study, was aimed to benefit from photovoltaic energy instead used electricity in irrigation water obtained from deep wells for irrigation of the Faculty of Agriculture Orchards Kahramanmaras Sutcu Imam University. In this context, is made cost analysis designed photovoltaic systems according to the irrigation water requirements of plants, the irrigation interval and given the required amount of irrigation water considering climatic conditions. In the cost analysis, was calculated as $0.06 \mathrm{TLm}^{-3}$ cost of water for 30 years. The system which investment costs 9029 TL will generate outside watering additional annual $2071.8 \mathrm{kWh}$ of electricity. The energy generated can be used for different purposes or by selling about can be obtained additional revenue 621 TL with price 2014 years. The total annual irrigation water requirements of the area is $5856.4 \mathrm{~mm}$. The amount of irrigation water is $2 \mathrm{ls}^{-1}$ in the July and August which months have the highest need of irrigation.
\end{abstract}

Keywords: Solar energy, Irrigation, Photovoltaic, Kahramanmaras

* e-mail: ucan@ksu.edu.tr 
Yılmaz Ş., Uçan K., Keten M., Narin N.

\section{Giriş}

Günümüzde sanayi, ulaşım, tarım gibi sektörlerin gelişmesiyle beraber enerji kullanımı artmıştır. Enerji ihtiyacını karşılayan en önemli kaynaklardan biri fosil yakıtlardır. Fosil yakıtların çevreye olan olumsuz etkileri, küresel 1sınma, fosil yakıt rezervlerin tükenmekte olması ve maliyetinin artması yenilenebilir enerji kaynaklarının kullanımını gündeme getirmiştir. Tarım sektöründe etkin olarak yararlanılabilecek başlıca yenilenebilir enerji kaynakları; güneş enerjisi, jeotermal enerji, rüzgar ve biyokütle enerjisidir [1]. Bu kaynaklar içinde de son yıllarda güneş enerjisi ön plana çıkmaktadır. Güneş enerjisi; potansiyeli, kullanım kolaylığı, temizliği, yenilenebilirliği ve çevre dostu olması gibi nedenler ile diğer yenilenebilir enerji kaynaklarına göre daha kolay bir şekilde yaygınlaşabilecek durumdadır. Güneş enerjisini elektrik enerjisine dönüştürebilmek için kullanılan PV sistemler, umut verici yenilenebilir enerji sistemlerinden biridir.

Dünyadaki bütün canlılar yaşamlarını devam ettirebilmek için suya ihtiyaç duyarlar. Bitkilerin yaşamları için gerekli olan fotosentezle besin üretimi bitkinin ancak kökleri aracılığıyla topraktan suyu almasıyla gerçekleştirilir. Bu sebeple sulama, yöntemine uygun olarak yapıldığında verimi artıran en önemli girdidir. Sulamanın olmadığı ya da yetersiz kaldığı alanlarda bitkisel üretim açısından düşüş gözlemlenir. Bitki gelişimini olumlu yönde artırmak, üretimde daha iyi sonuçlar alabilmek ve verim elde edebilmek için sulama son derece önemlidir. Kazançlı bir üretim yapabilmenin önemli şartlarından biriside, bütün girdilerde olduğu gibi, suyunda uygun zamanda ve uygun miktarda ve minimum maliyetle kullanılmasıdır. Ülkemizin coğrafi konumu itibariyle, topraklarımızın büyük bir bölümünün sulama suyuna ihtiyacı vardır. Bitkilerin suya ihtiyaç duyduğu dönemin ve bir defada verilecek sulama suyu miktarının belirlenmesi, bilinçli bir sulama yapmanın ön şartıdır. Ayrıca sulama suyunun uygun zamanda yeterli sayıda ve miktarda verilmesi bitkisel üretim, en az enerji ve işletme gideri ile sağlanması da girdilerin azaltılması açısından önemlidir.

Tarım sektöründe son yıllarda sulama uygulamalarında enerji tüketiminin azaltılmasına yönelik olarak yapılan araştırmalar; sulama amacıyla yeni ve yenilenebilir doğal enerji kaynaklarının kullanılmasına ve fosil yakıtların tüketildiği geleneksel sistemlere alternatif olarak, düşük maliyetli ve etkinliği yüksek sulama sistemlerinin geliştirilmesine yöneliktir. En önemli yenilenebilir enerji kaynağ1 olan güneş enerjisinden tarımsal sulama amacıyla yararlanılması durumunda, özellikle uzun vadeli yatırımlarda toplam üretim giderleri içerisinde büyük yer tutan sulama giderleri azalacak ve buna bağlı olarak üretim maliyeti de azalacaktır [2]. Alışılagelen enerji kaynaklarından elde edilen enerji bedellerinin yüksek olması nedeniyle, tarımsal sulama amacıyla yeni ve yenilenebilir enerji kaynaklarından yararlanmak büyük önem kazanmıştır. Sulama uygulamalarında, günümüz enerji varlığını korumak ve çevre kirlenmesini önlemek amacıyla fosil enerji kaynakları yerine, yenilenebilir enerji kaynaklarından yararlanılması öncelikli bir gereksinimdir.

Sulama suyunun elde edilmesinde yüzey sulama kaynakların yanında yeraltı suları da kullanılmaktadır. Yeraltı sularının yüzeye çıkarılmasında ve sulama sistemine verilmesinde enerji kaynağı ve maliyeti ciddi bir problem oluşturmaktadır. Her zaman arazide elektrik kaynağına erişim kolay değildir. Maliyeti yüksek olmasına rağmen hala dizel yakıtla çalışan pompalar kullanılmaktadır. Enerji maliyetlerinin yüksek olması sulama yapan çiftçilerin en büyük sorunudur. Güneş enerjisi alanında olan gelişmeler, çiftçilerin sulama için enerji ihtiyaçlarının karşılanması açısından umut vericidir. 
Güneş enerjisinin başarılı olduğu alanlardan biriside tarımsal sulama sistemleridir. PV sulama sistemleri yeni gelişen teknolojiyle birlikte alternatif sulama sistemleri haline gelmiştir [3]. PV sulama sistemlerinde gerekli olan enerji güneş enerjisinden karşılanmaktadır. PV (güneş pilleri) paneller yüzeylerine gelen güneş ışınım enerjisini elektrik enerjisine dönüştürebilen, bakımı kolay ve uzun ömürlü yarı iletken elektronik sistemlerdir. Pilin verdiği elektriğin kaynağı yüzeyine gelen güneş enerjisidir. Güç üretimi amacıyla kullanılan güneş pilleri güneş 1şığı düştüğü zaman uçlarında elektrik gerilimi oluşur. Işık yarı iletken malzemeye ulaştığında malzeme tarafından emilir. Malzemedeki iyonlar bağlarını zayıflatır ve pozitif bölgeden negatif bölgeye hareket ederek elektrik akımı oluşturur. Yarı iletken üzerine koyulan metal toplayıcılar bu elektrik akımını toplayarak sisteme verir. Bu sayede elektrik enerjisi elde edilmiş olur.

Fotovoltaik pillerin uygulama alanları, kırsal bölgelerin elektrifikasyonu, zirai uygulamalar (süt, gıda korunması), haberleşme cihazları, uyarı ve sinyalizasyon sistemleri, meteoroloji aletleri, park ve otoyolların aydınlatması, su pompalanması ve küçük tip el aletleri olmak üzere sıralanabilir. Fotovoltaik pillerin diğer uygulama alanı ise güneş santralleridir. En fazla fotovoltaik üretim kapasitesi Almanya, İtalya, İsviçre ve İspanya'dadır. PV teknolojisi temiz teknoloji olduğundan, karbondioksit vergisi ve emisyon yönünden gelecek y1llarda fosil yakıtlara göre daha cazip duruma gelecektir [4].

Atay ve ark., [5] tarafından Şanlıurfa koşullarında PV mikro sulama sistemi kurulumu ile ilgili bir çalışma sonucunda sistemin ilk yatırım maliyetinin yüksekliği ve sistem veriminin düşüklüğü dezavantaj olarak görülürken su tüketimine yönelik sorunları gidermede en uygun çözümlerden biri olarak önerilmiştir.

Bu çalışmada, değişik meyve türlerinin bulunduğu meyve bahçesinde bitkilerin su ihtiyaçlarına bağlı olarak hazırlanan sulama programı için gerekli olan sulama suyunun PV jeneratör beslemeli derin kuyudan elde edilmesi planlanmıştır. Bu amaçla alanda yetiştirilen bitkilerin sulama suyu ihtiyaçları hesaplanarak, gerekli olan güneş enerjili sulama sisteminin optimum planlanması ve sistemin maliyet analizi yapılmıştır.

\section{Materyal ve Metot}

\subsection{Araştırma Alanının Konumu, Toprak ve İklim Özellikleri}

Araştırmada, Kahramanmaraş Sütçü İmam Üniversitesi yerleşke alanında 64.5 da'llk alanı kapsayan meyve bahçesi ele alınmıştır. Alanın denizden ortalama yüksekliği $506 \mathrm{~m}$ olup $37^{\circ} 36^{\prime} \mathrm{K}, 36^{\circ}$ 49' D enlem ve boylamlarında yer almaktadır. Bahçede elma, armut, üzüm, kiraz, nar, erik, böğürtlen, ahududu, dut, şeftali ve incir meyve türleri yetiştirilmektedir. Araştırmanın yürütüldüğg̈ arazi, güneykuzey yönünde eğimli, derin, drenajı iyi, kireç ve organik madde bakımından orta derecede zengin, yerçekimi etkisi ile tasınmış killi ve kollüviyal özellikteki koyu kahve renkli topraklara sahiptir. Alanda 0-90 cm katmanlardan alınan bozulmuş ve bozulmamış toprak örneklerinden tarla kapasitesi \%36.04$41.19(\mathrm{Pw})$, solma noktası \%20.43-24.17 (Pw), hacim ağırlı̆̆ı 1.23-1.33 $\mathrm{gcm}^{-3}$ ve bünye killi-tınlı olarak belirlenmiştir. Çalışma alanı toprağın pH'sı 7.23-7.80 ve elektriksel iletkenliği $0.022-0.018 \mathrm{dSm}^{-1}$ arasında değişmektedir. Meyve bahçesinin fotovoltaik jeneratör güç sistemi ile çalışan derin kuyu sulama sistemi ile optimum sulanması planlanmıştır. Şekil 1'de çalışma alanı görülmektedir. 
Fotovoltaik sistem tasarımı için gerekli olan Kahramanmaraş ili merkez ilçesine ait uzun yıllık (1975-2013) bazı iklim parametreleri Tablo 1'de verilmiştir. Araştırmanın yürütüldüğü alan yazları sıcak ve kurak, kışları 1lık ve yağışlı geçen Akdeniz iklim kuşağında yer almaktadır. Ayrıca bölge ülkemizin en yüksek güneş enerjisi potansiyeline sahip olan Güneydoğu Anadolu ve Akdeniz Bölgelerine sınırdır.

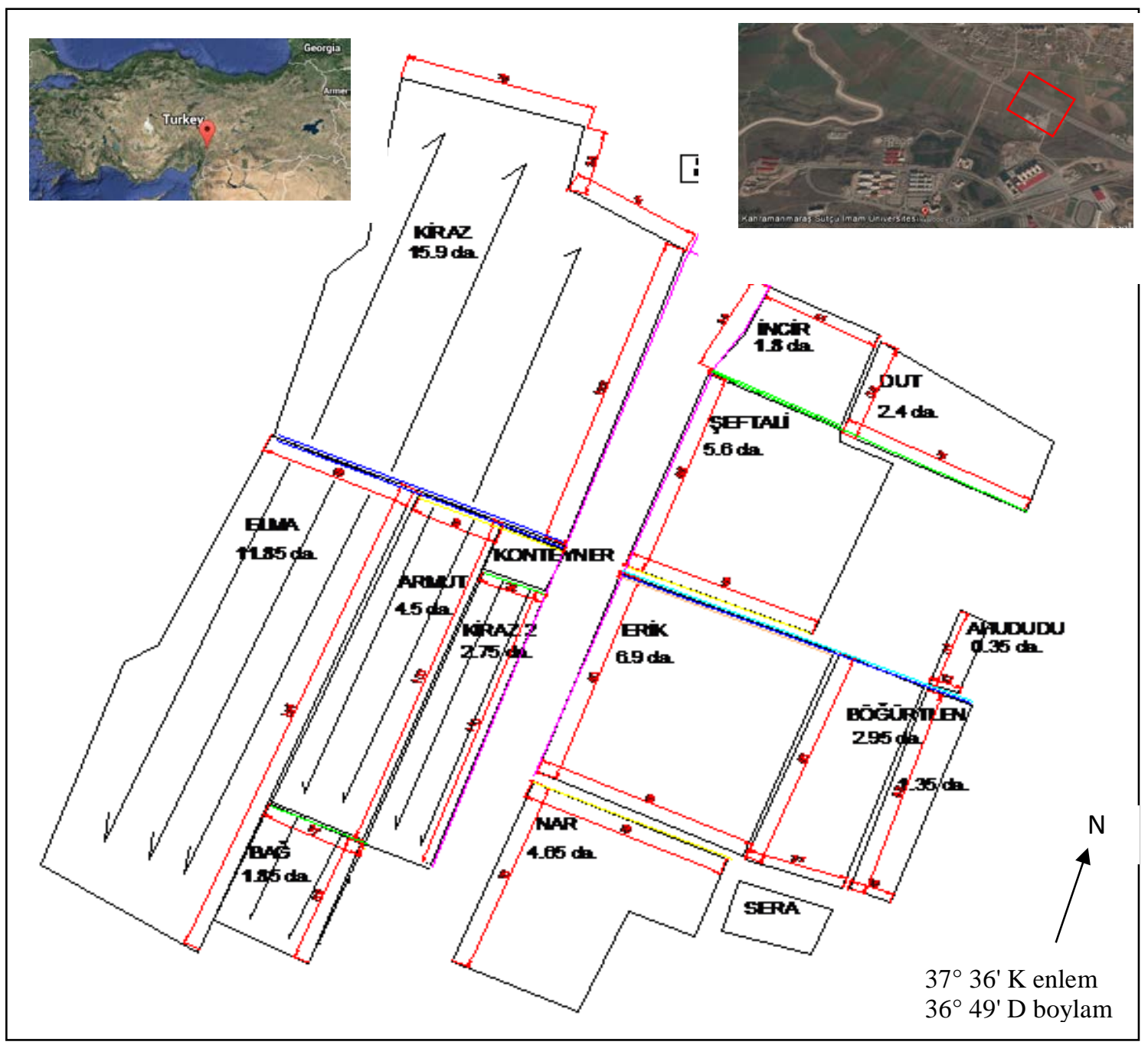

Şekil 1. Çalışma alanı

Tablo 1. Kahramanmaraş ilinin merkez ilçesine ait uzun yıllar ortalama bazı iklim parametreleri [6]

\begin{tabular}{|c|c|c|c|c|}
\hline Aylar & Işınım $\left(\mathrm{kWhm}^{-2}\right)$ & Güneşleme süresi (saat) & Sicaklık $\left({ }^{\circ} \mathrm{C}\right)$ & Rüzgâr $\left(\mathrm{ms}^{-1}\right)$ \\
\hline Ocak & 59.70 & 4.21 & 4.43 & 2.10 \\
\hline Şubat & 77.40 & 5.47 & 4.97 & 2.30 \\
\hline Mart & 125.10 & 6.61 & 9.03 & 2.50 \\
\hline Nisan & 152.70 & 7.85 & 13.91 & 2.50 \\
\hline Mayıs & 188.70 & 9.57 & 20.19 & 2.60 \\
\hline Haziran & 204.30 & 11.49 & 26.01 & 3.30 \\
\hline Temmuz & 203.10 & 12.07 & 30.36 & 3.60 \\
\hline Ağustos & 180.00 & 11.43 & 29.25 & 3.00 \\
\hline Eylül & 151.80 & 10.13 & 24.03 & 2.60 \\
\hline Ekim & 113.40 & 7.55 & 18.00 & 2.00 \\
\hline Kasım & 72.00 & 5.56 & 10.78 & 1.80 \\
\hline Aralık & 54.30 & 3.86 & 5.91 & 1.90 \\
\hline
\end{tabular}




\subsection{Sulama Suyu İhtiyacı}

Araştırma alanında yetiştirilen bitkilerin referans su tüketimleri Gıda Tarım Örgütü (Food and Agriculture Organization, FAO) tarafindan geliştirilen CROPWAT (8.0) paket programı yardımıyla Penman-Monteith yöntemine göre hesaplanmıştır [7]. Referans bitki su tüketimi elde edildikten sonra, alanda tarımı yapılan bitkilerin $\mathrm{k}_{\mathrm{c}}$ bitki katsayısı değerleri İlbeyi [8] tarafından yapılan doktora tez çalışmasından elde edilmiştir. Bu çalışmada farklı bölgeler için verilen kc katsayılarından bölge şartlarına uygun (geçiş bölgeleri) olan katsayılar kullanılarak gerçek su tüketimi değerleri bulunmuştur. Hesaplanan bitki su tüketiminin yağışlarla karşılanan miktarının belirlenmesi amacıyla yöre için verilen aylık ortalama yağış miktarları dikkate alınarak etkili yağış miktarları USDA Toprak Koruma Servisinin geliştirdiği eşitliğe göre hesaplanmıştır [9]. Bitki paterni için gerekli olan ekim alanı ve oranları, örtü yüzdeleri ve bitkilerin dönemlik vejetasyon süreleri bölge koşullarına göre belirlenerek meyve bahçesi için gerekli olan sulama suyu miktarları hesaplanmıştır.

\subsection{Fotovoltaik Sulama Sistemi}

Fotovoltaik sulama sistemi, Fotovoltaik paneller, invertör, kontrol paneli ve doğru akımla (DC) çalışan dalgıç pompadan oluşmaktadır. Çalı̧̧mada fotovoltaik panel olarak Sunpower marka, $262 \mathrm{~W}$ gücünde, mono kristal panel kullanılmıştır. Sistem uyumu açısından 3 adet panel seri olarak olmak üzere 9 adet panel kullanılmıştır (Şekil 2). Toplam panel gücü $2.4 \mathrm{~kW}$ olup $1.5 \mathrm{~kW}$ gücünde DC dalgı̨̧ pompa kullanılmıştır.

Sistemde kullanılan sulama kuyusunun derinliği $112 \mathrm{~m}$ olup y1llık ortalama su derinliği 15.9 m'dir. Sulama kuyusuna ait aylık su seviyesi değişim grafiği Şekil 3'de verilmiştir. Kuyu havuz arası 300 m, havuz hacmi $286 \mathrm{~m}^{3}$ havuza giden 6 atm basınca dayanımlı PE borunun çapı $180 \mathrm{~mm}$, kuyuda $10 \mathrm{~atm}$ basınca dayanımlı PVC borunun çapı 40 mm'dir.

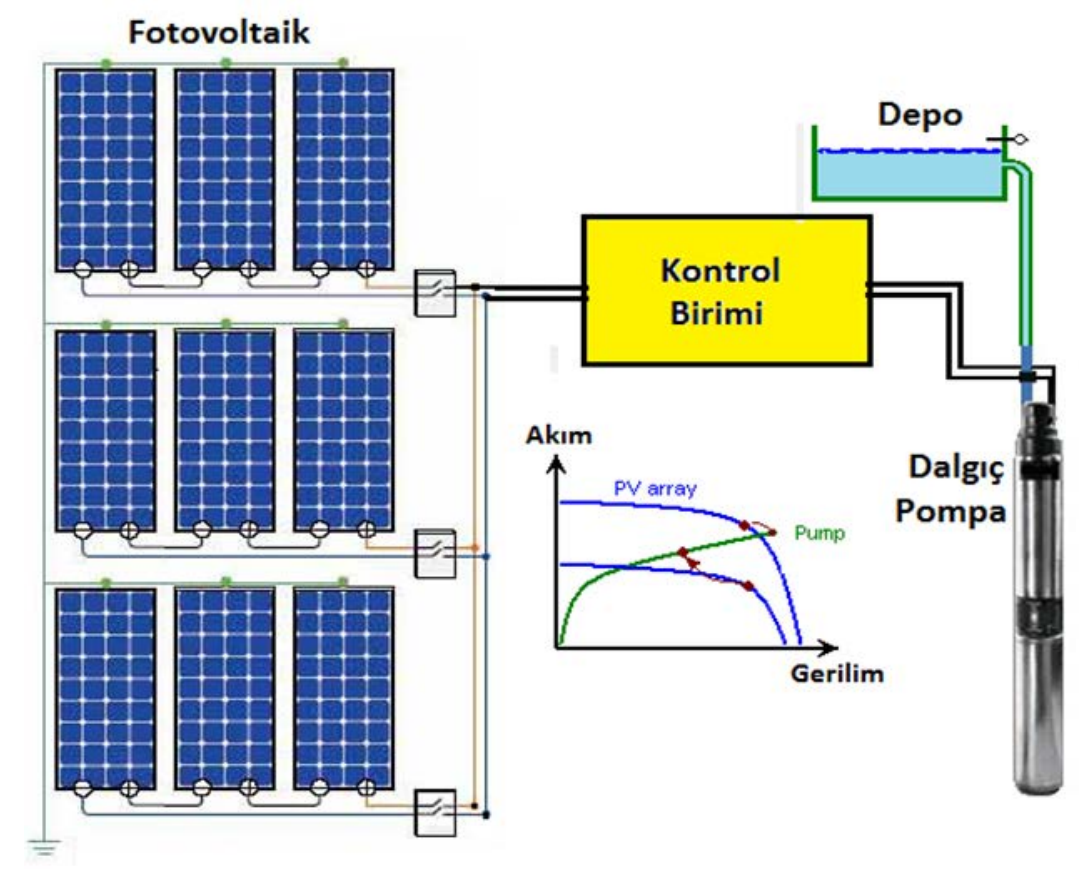

Şekil 2. Sulama Sistemi 
Yılmaz Ş., Uçan K., Keten M., Narin N.

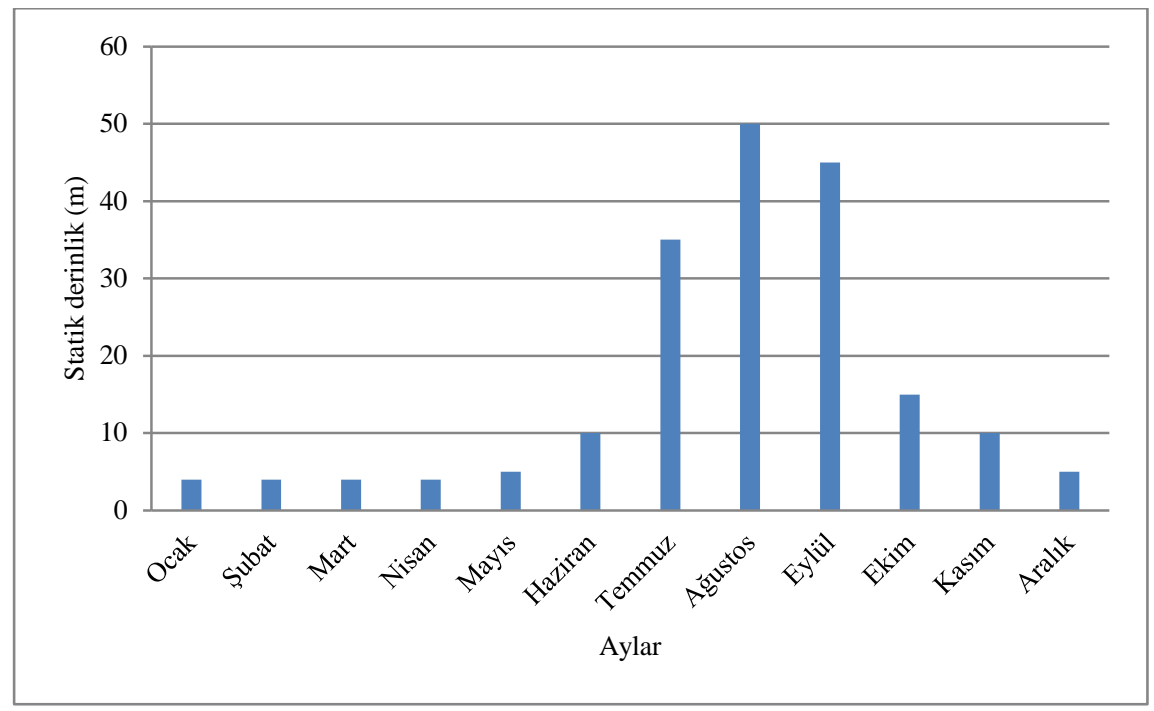

Şekil 3. Kuyudaki su seviyesi derinliğinin aylık değişimi

DC dalgıç pompa $1.5 \mathrm{~kW}$ gücünde olup minimum MPPT gerilimi $100 \mathrm{~V}$ ve Maksimum MPPT gerilimi 140 volttur. Nominal çalışma gerilimi 120 volt, maksimum akım 15 Amper ve maksimum güç 1960 wattır. Pompa verimi \% 94’dür. Pompa akış hızı-derinlik karakteristiği Şekil 4’de, Kullanılan fotovoltaik panellerin etiket değerleri Tablo 2'de görülmektedir.

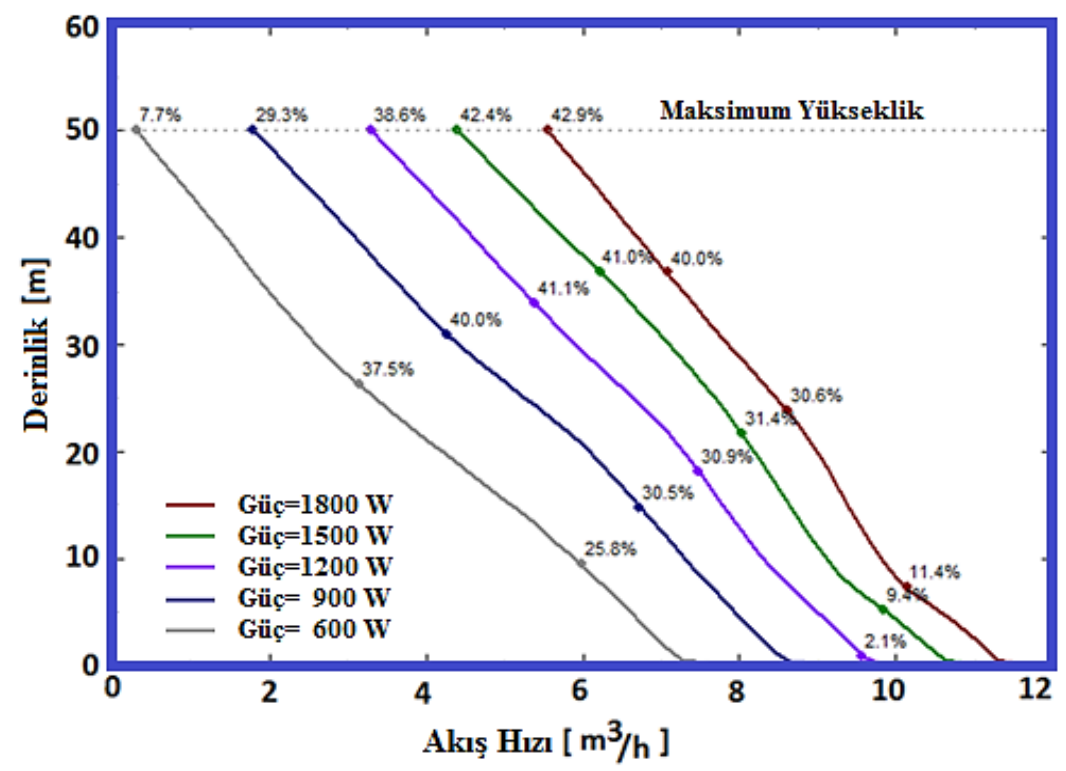

Şekil 4. Pompa akış hızı-derinlik karakteristiği

Tablo 2. Fotovoltaik panel değerleri

\begin{tabular}{|c|c|c|c|}
\hline Özellikler & Değerler & Özellikler & Değerler \\
\hline Teknoloji & Si-mono & Verim & \%21.11 \\
\hline Max Güç (Pmax) & $262 \mathrm{~W}$ & Boy & $1559 \mathrm{~mm}$ \\
\hline Nominal Voltaj (Vmp) & $43.30 \mathrm{~V}$ & En & $789 \mathrm{~mm}$ \\
\hline Açık Devre Gerilimi (Voc) & $51.40 \mathrm{~V}$ & & \\
\hline
\end{tabular}


Fotovoltaik panelin modellenmesi için bir diyotlu eşdeğer devre kullanılmıştır. Modelde seri direnç $0.329 \Omega$, paralel direnç $2583 \Omega$ olarak hesaplanmıştır. Panelde bulunan 72 hücre seri olarak bağlanmıştır. Güç sisteminde 9 adet $262 \mathrm{~W}$ gücünde mono kristal panel kullanılmıştır. Panelin nominal gerilimi 43.3 V, nominal akımı 6.05 A olup, verimi \% 21.11'dir. Fotovoltaik panelin güç-gerilimi Şekil 5'de, akım-gerilim karakteristikleri ise Şekil 6'da verilmiştir.

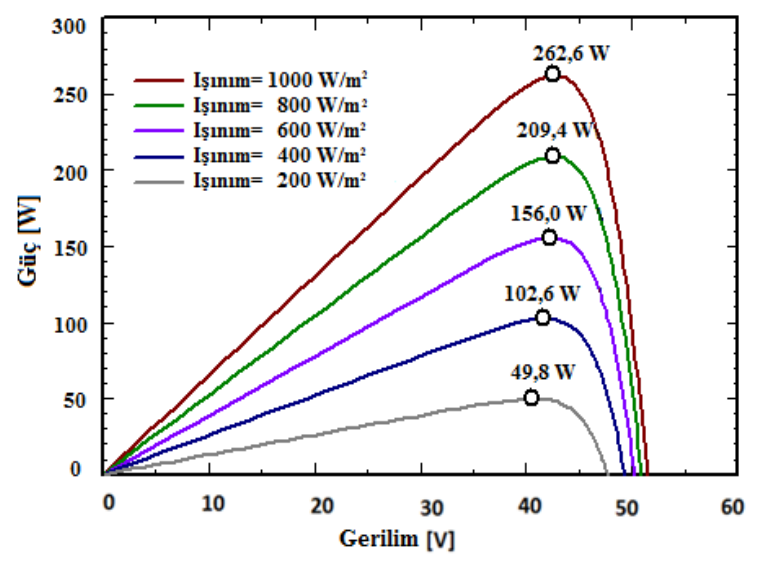

Şekil 5. PV güç-gerilim karakteristiğ

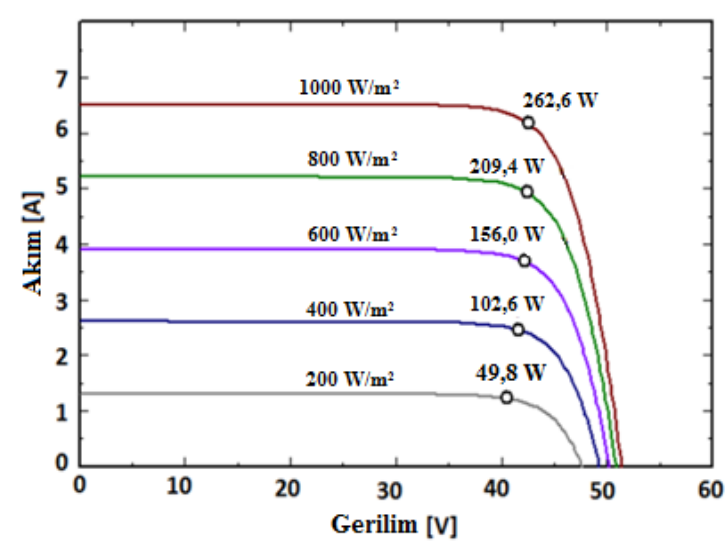

Şekil 6. PV akım-gerilim karakteristiği

\section{Bulgular ve Tartişma}

\subsection{Sulama Suyu İhtiyacı}

Meyve bahçesinin sulama suyu ihtiyacı, güneşlenme süresi, sulanan alan, örtü yüzdesi ve sulama suyu miktarı değerleri Tablo 2'de verilmiştir. Tablo 2. incelendiğinde meyve bahçesinin aylık toplam sulama suyu miktarı sulama sezonunun başlangıcı olan Nisan ayında $105.59 \mathrm{~mm}$ olup bu değer Temmuz ayına kadar artış göstererek 1507.8 mm'ye ulaşmakta daha sonra sulama sezonunun sonu olan Ekim ayına kadar azalan oranlarda bir seyir izleyerek 196.9 mm'ye ulaşmaktadır. Yıllık meyve bahçesi için gereksinim duyulan toplam sulama suyu ihtiyacı 5856.4 mm'dir. Damla sulama yönteminin uygulandığı alan yarı kurak bir bölge olduğu için toplam alanın en az \%30'unun sslatılması (Islatılan alan oranı, P) gerektiği kuralı sistemde gerçekleştirilmiştir [10].

Tablo 2. Meyve bahçesinin sulama suyu ihtiyacı, güneşlenme süresi, sulanan alan, 1slatılan alan oranı ve sulama suyu miktarı değerleri

\begin{tabular}{|c|c|c|c|c|c|c|c|}
\hline Aylar & $\begin{array}{l}\text { Net sulama } \\
\text { suyu miktarı } \\
\left(\mathrm{mm} \mathrm{gün}^{-1}\right)\end{array}$ & $\begin{array}{c}\text { Güneşlenme } \\
\text { süresi } \\
\text { (saat) }\end{array}$ & $\begin{array}{c}\text { Sulanan } \\
\text { alan } \\
\text { (da) }\end{array}$ & $\begin{array}{l}\text { Islatılan } \\
\text { alan } \\
\text { oranı } \\
\text { (P) }\end{array}$ & $\begin{array}{l}\text { Net sulama } \\
\text { suyu } \\
\text { miktarı } \\
\left(\text { m }^{3} \text { gün }\right.\end{array}$ & $\begin{array}{c}\text { Güneşlenme süresine } \\
\text { göre net sulama suyu } \\
\text { miktarı }\left(\mathrm{ls}^{-1}\right)\end{array}$ & $\begin{array}{c}\text { Toplam sulama suyu } \\
\text { ihtiyacı }(\mathrm{mm})\end{array}$ \\
\hline Nisan & 0.4 & 7.85 & 64.5 & 0.3 & 7.7 & 0.3 & 105.5 \\
\hline Mayıs & 1.5 & 9.57 & 64.5 & 0.3 & 29.0 & 0.8 & 488.2 \\
\hline Haziran & 3.7 & 11.49 & 64.5 & 0.3 & 71.6 & 1.7 & 1193.6 \\
\hline Temmuz & 4.5 & 12.07 & 64.5 & 0.3 & 87.1 & 2.0 & 1507.8 \\
\hline Ağustos & 4.2 & 11.43 & 64.5 & 0.3 & 81.3 & 2.0 & 1389.5 \\
\hline Eylül & 3.0 & 10.13 & 64.5 & 0.3 & 58.1 & 1.6 & 955.0 \\
\hline Ekim & 0.6 & 7.55 & 64.5 & 0.3 & 11.6 & 0.4 & 196.9 \\
\hline
\end{tabular}




\subsection{Fotovoltaik Sulama Sistemi}

Meyve bahçesinin fotovoltaik jeneratör güç sistemi ile çalışan derin kuyu sulama sistemi için geliştirilen fotovoltaik sulama sisteminin bir yıl için üretilen ve pompada kullanılan enerjinin günlük ve aylık değişim değerleri Şekil 7 ve 8'de verilmiştir.

Şekil 7. incelendiğinde sonbahar ve kış aylarında havanın bulutlu oluşuna ve gün uzunluğuna bağlı olarak ilkbahar ve yaz aylarına göre üretilen PV enerji miktarları değişiklik göstermiştir. En yüksek enerji miktarı Temmuz ayında (471.6 kWh) üretilirken, en düşük enerji miktarı ise Şubat ayında (255.2 $\mathrm{kWh}$ ) olarak gerçekleşmiştir.

Şekil 8. incelendiğinde PV sistemde aylık ortalama $371.7 \mathrm{kWh}$, yllık toplam ise $4460.5 \mathrm{kWh}$ enerji üretilmektedir. Sulama sezonun dışında kalan Ocak, Şubat, Mart, Kasım ve Aralık aylarında panelde üretilen $1476 \mathrm{kWh}$ enerjinin tamamı fazla enerjidir. Su depolama havuzunun hacmi $286 \mathrm{~m}^{3}$ olup, yıllık sulama suyu ihtiyacı $10505 \mathrm{~m}^{3}$ 'tür. Bu suyun derin kuyudan toprak yüzeyine çıkarlıp depoya aktarılması için $2115.2 \mathrm{kWh}$ enerji kullanılmaktadır. Yıllık üretilen toplam enerjiden $2071.8 \mathrm{kWh}$ ise fazla enerji olup başka amaçlar için kullanılabilir veya şebekeye satılarak yaklaşı 621 TL gelir elde edilebilir.

Saka [11] tarafından yapılan çalışmada elektrik nakil hattı çekildiğinde $\mathrm{kW}$ başına maliyet ile PV kullanıldığında $\mathrm{kW}$ başına maliyeti araştırmış, ve yapılan hesaplamalar sonucunda PV'nin daha avantajlı olduğu sonucuna varmıştır. Rüstemli ve ark., [12] PV modüllerin ömür sürelerinin 30 yll olduğu düşünülürse yapılan yatırımın yaklaşık 5 yıllık bir sürede geri alınabileceğini belirtmişlerdir.

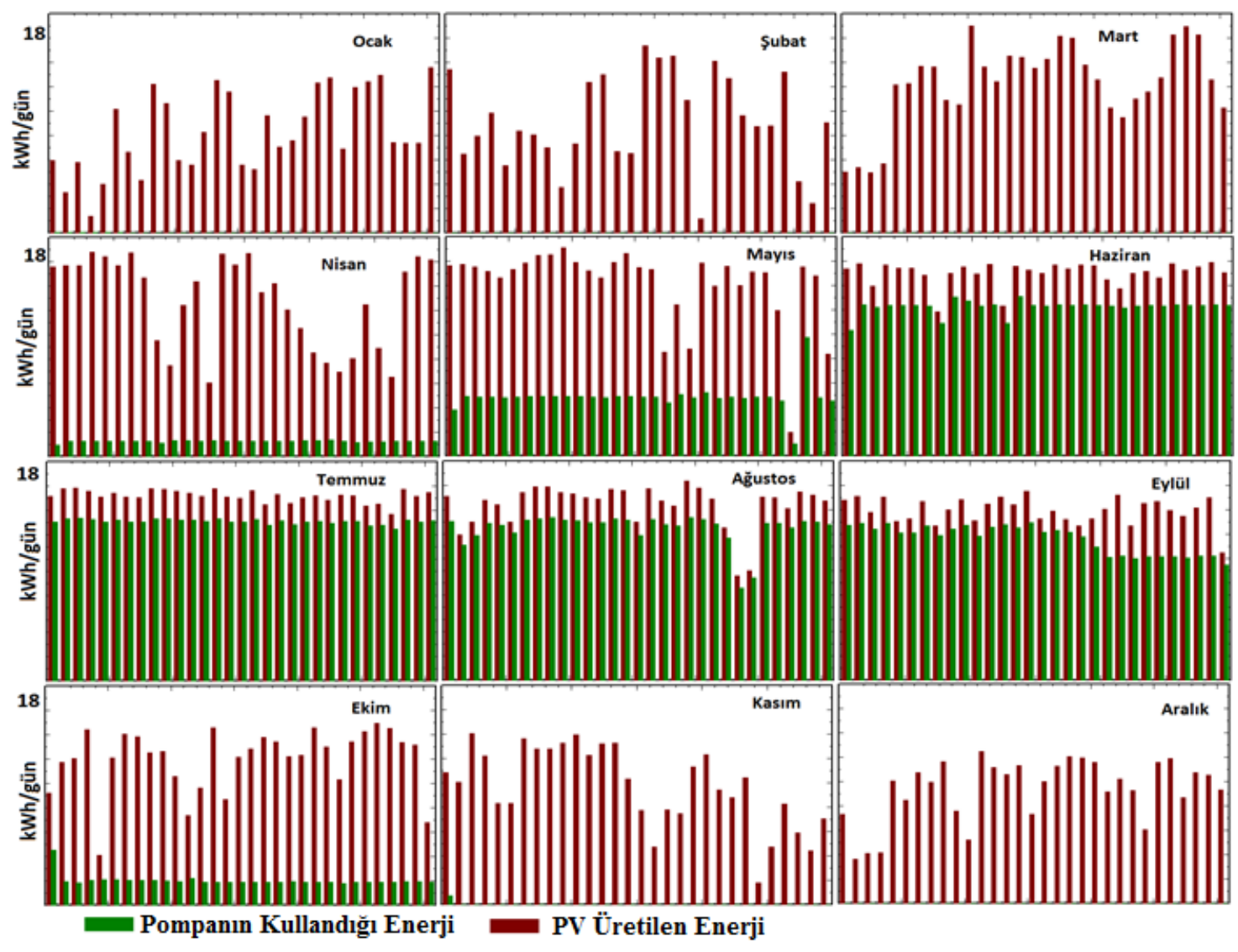

Şekil 7. Üretilen ve pompada kullanılan enerjinin günlük değişimi 


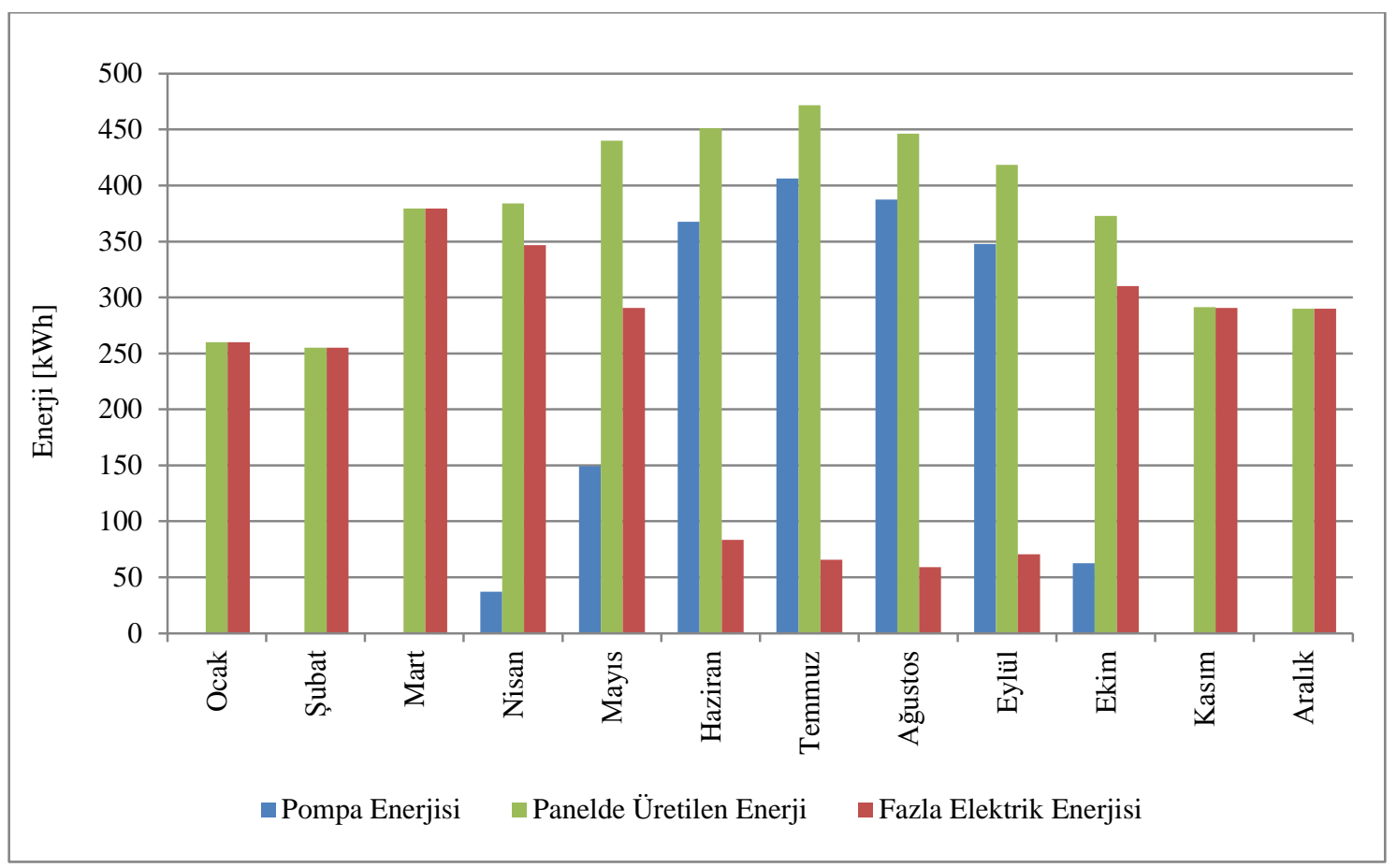

Şekil 8. Panelde üretilen, pompada kullanılan ve fazla elektrik enerjisinin aylık değişimi

\section{Sonuç ve Öneriler}

Dünyada artan enerji talebine karşıllı azalan doğal kaynaklar bilim insanlarının alternatif yollar aramasına sebep olmuştur. Doğal kaynakları daha uzun süre elde tutabilmek ve onlardan ekonomik anlamda fayda sağlamak için birçok sektörde enerjiyi elde tutabilme anlamında iyileştirme yapılması gerekmektedir. Bunların başında da azalmakta ve pahalı olan fosil kaynaklardan enerji elde etmek yerine doğada hali hazırda bulunan ancak doğrudan kullanılması için ekipman ve kurulum gerektiren yenilenebilir kaynaklar tercih edilmelidir. Özellikle temiz ve ekonomik olmasından dolayı güneş enerji sistemleri tarım sektöründe en büyük sıkıntılardan biri olan enerji ihtiyacını karşılama konusunda başvurulmalıdır.

Yapılan çalışma Kahramanmaraş iklim şartlarında yenilenebilir enerji kaynaklarından güneş enerjisi ile ekonomik sulama yapılabileceğini göstermiştir. Çalışmada Fotovoltaik sulama sisteminde 30 yıl için yapılan maliyet analizinde suyun $\mathrm{m}^{3}$ ü $0.06 \mathrm{TL}$ olarak hesaplanmıştır. Yatırım maliyeti $9029 \mathrm{TL}$ olup, sulama dışında yıllık $2071.8 \mathrm{kWh}$ elektrik enerji fazladan üretilmektedir. Fazla olan enerji başka amaçlar için kullanılabilir veya şebekeye satılarak yaklaşık 621 TL gelir elde edilebilir. Ayrıca Uluslararası Enerji Ajansı (IEA)'na göre Türkiye için $1 \mathrm{kWh}$ elektrik enerjisi üretimi için 489 gCO $_{2}$ salınımı yaptığı dikkate alınırsa fotovoltaik sulama sistemi ile 4.33 ton $\mathrm{CO}_{2}$ salınımını engellediği ortaya çıkmıştır.

Yenilenebilir enerji kaynaklarından güneş enerjisinin PV sistemlerle tarım sektöründe kullanılması kırsal kesimde yaşayan çiftçilere ekonomik açıdan katkı sağlayacaktır [13]. Bu durum kırsal kesimden şehirlere doğru olan göçü azaltacak, temiz enerji kullanımından dolayı da kırsal kesimin daha yaşanabilir hale gelmesine imkan tanıyacaktır. 


\section{Kaynaklar}

[1] Öztürk, H.H., “Bitkisel üretimde enerji yönetimi.” Hasad Yayıncılık, İstanbul, 256 s, 2011.

[2] Senol, R., “An analysis of solar energy and irrigation systems in Turkey.” Energy Policy 47: 478486, 2012.

[3] Glasnovic, Z., Margeta, J., “A model for optimal sizing of hotovoltaic irrigation water pumping systems.” Solar Energy 81: 904-916, 2006.

[4] Anonim, “Dünya’da ve Türkiye'de güneş enerjisi.” DEK-TMK Yayın No: 0011, EKC Form Ofset, Ankara, 246 s. 2009

[5] Atay, Ü., Işıker, Y., Yeşilata, B., "Fotovoltaik Güç Destekli Mikro Sulama Sistemi Projesi Genel Esasları", V. Yenilenebilir Enerji Kaynakları Sempozyumu, Diyarbakır, 2009

[6] Anonim, “1975-2013 uzun yıllık aylık meteoroloji verileri.” Kahramanmaraş Meteoroloji Il Müdürlüğü Envanter Kayıtları, Kahramanmaraş, 2013

[7] Beyribey, M., "GAP sulama projelerinde sulama suyu ihtiyacı ve sistem kapasitesi üzerinde bir araştırma.” Ankara Üniversitesi Ziraat Fakültesi Yayınları, Yayın No: 1245, Ankara, 1992

[8] İlbeyi, A., “Türkiye’de bitki su tüketimleri tahmininde kullanılacak bitki katsayılarının belirlenmesi”. Ankara Üniversitesi, Fen Bilimleri Enstitüsü, Doktora Tezi, 179 s, 2001

[9] Ünlükalaycı, A., “Konya Ilgın Atlantı Ovası sulamasında su dağıtım ve kullanım etkinliği”. Ankara Üniversitesi, Fen Bilimleri Enstitüsü, Doktora Tezi, 134 s, 1994

[10] Yıldırım, O. "Sulama Sistemlerinin Tasarımı." Ankara Üniversitesi Ziraat Fakültesi Yayınlarl, Yayın No: 1594, Ankara, 2013

[11] Saka, Ö., "Konya Koşullarında Güneş Pillerinin Aydınlatma Uygulamalarında Kullanım İmkanları." Selçuk Üniversitesi Fen bilimleri Enstitüsü, Yüksek Lisans Tezi, Konya, 2007

[12] Rustemli, S., Dinçadam, F., Demirtaş, M., "Güneş Pilleri ile Sıcak Su Elde Etme ve Sokak Aydınlatması", V. Yenilenebilir Enerji Kaynakları Sempozyumu, 19-21 Haziran, Diyarbakır, 2009

[13] Periasamy, P., Jain, N.K., Singh, I.P. “A review on development of photovoltaic water pumping system.” Renewable and Sustainable Energy Reviews 43: 918-925, 2015 